\title{
Stafne's Bone Defect in Atypical Location: Between the Subcondylar Region and Neck of the Mandible Ramus
}

\author{
Francisco Barbosa de Araújo Neto*, Stefanie Gallotti Borges Carneiro, \\ Dalton Yukio Araújo Fugita, Flávio Henrique Martins Lessa, José Dilermando Gotardo, \\ Vinícius Martins Valois, Raphael Gomes Teixeira, Tiago Bezerra Albano, Erick Falci Santos
}

Department of Radiology at Hospital Heliópolis, São Paulo, Brazil

Email: *Bilbanmaster@gmail.com, Stefaniegallotti@hotmail.com, Dfugit@gmail.com, Flaviohmlessa@hotmail.com, Josedigotardo@gmail.com, Viniciusmvalois@gmail.com, Raphagtx@gmail.com,Tiagob.albano@gmail.com,Erickfalci2@gmail.com

How to cite this paper: De Araújo Neto, F.B., Carneiro, S.G.B., Fugita, D.Y.A., Lessa, F.H.M., Gotardo, J.D., Valois, V.M., Teixeira, R.G., Albano, T.B. and Santos, E.F. (2017) Stafne's Bone Defect in Atypical Location: Between the Subcondylar Region and Neck of the Mandible Ramus. Open Journal of Medical Imaging, 7, 124-129. https://doi.org/10.4236/ojmi.2017.73012

Received: August 31, 2017

Accepted: September 19, 2017

Published: September 22, 2017

Copyright (c) 2017 by authors and Scientific Research Publishing Inc. This work is licensed under the Creative Commons Attribution International License (CC BY 4.0).

http://creativecommons.org/licenses/by/4.0/

\begin{abstract}
CONTEXT: Stafne's bone defect is a benign lesion appearing on the image as a round radiolucent lesion within a cortical defect on the mandible. CASE REPORT: We attend one 46-year-old male patient came for diagnostic evaluation of a rounded and radiolucent lesion in the transition of the subcondylar region and neck of the left mandible ramus incidentally found by a dentist. Computed tomography and magnetic resonance imaging were performed in medical radiology and a Stafne's cyst was diagnosed in an atypical location. CONCLUSION: We emphasize that Stafne's bone defect is a benign lesion, whose imaging diagnosis can be conclusive, avoiding unnecessary surgical procedures.
\end{abstract}

\section{Keywords}

Tomography, Stafne's Bony Defect, Mandible

\section{Introduction}

Stafne bone cavity is a rare abnormality, named after Edward Stafne, who first described the lesion in 1942. The lesion is known by many synonyms, such as Stafne lacune, static bone cavity, latent bone cyst and lingual mandibular bone depression. Lingual mandibular depressions represent a group of focal defects in the lingual surface of the mandible, mimicking a cystic lesion on plain radiographs. The pathogenesis is believed to be caused by the pressure of the submandibular glands against lingual cortical bone of the mandible. It is usually an incidental, 
stable and benign finding, and for this reason many authors have proposed that there is no need for treatment of these bone defects on the lingual side of the mandible. The posterior mandible region, particularly at the angle and below the mandibular canal, is the common location. However, patients may present anatomical variations, making the diagnosis challenging, often confusing with injuries of another nature and leading to unnecessary treatments. Because of this, it is interesting to know the possible anatomical variations, to make the correct diagnosis and not to cause injuries to the patient [1] [2] [3].

We will report a case of Stafne's bone cyst with an atypical presentation. Patients may have anatomical variations, making the diagnosis essential and challenging for effective management, avoiding unnecessary treatments.

\section{Case Report}

A 46-year-old asymptomatic male was admitted to the medical radiology service to investigate a lesion in the left jaw that was incidentally found in an external dental service. He performed computed tomography and magnetic resonance imaging of mandibular region. A rounded, well circumscribed and unilocular lesion was visualized at the transition between the subcondylar region and the neck of the left mandible ramus, with a fatty, soft tissue and vascular component inside. The patient was followed for one year after the initial diagnosis and there were no signs of aggressive behavior or malignancy, as verified by computed tomography and magnetic resonance imaging. Therefore, a hypothesis of a bone defect or Stafne cyst was confirmed in an atypical location in the mandible, near the deep portion of the adjacent parotid.

\section{Discussion}

In 1942, Edward Stafne reported 35 radiolucent lesions in the mandibular angle discovered on intraoral dental films. These radiolucencies are called nowadays as Stafne bone cavities. Other synonyms include: static bone cavity, latent bone cyst, bone defect of the mandible development, Stafne cyst and bone depression of the mandibular lingual cortical [4].

Recent studies support that this condition may be originated from pressure due to hyperplasia and hypertrophy of the salivary glands towards the adjacent bone surface, leading to bone remodeling in response to chronic stimuli in the cortical area. This theory could also explain the existence of anterior defects associated with the sublingual glands and defects in the ascending branches associated with the parotid glands [2] [5].

Stafne's bone defect is usually asymptomatic, with a male predominance, at a ratio of 6:1, appearing between the fifth and sixth decade of life [3] [5] [6]. It is a rare finding in the population, with incidence ranging from $0.1 \%$ to $0.48 \%$ [5] [7] [8].

Imaging studies are indispensable for diagnosis because they provide accurate information about the soft and hard tissues in question, without the need to ex- 
pose the patient to surgical or invasive procedures. Radiographic images are usually helpful to diagnose this type of lesion. It is presented as a rounded defect or a well-defined focal depression of mandibular lingual cortical bone with preservation of vestibular cortical bone, varying from 10 to $30 \mathrm{~mm}$ in diameter, often located below the mandibular canal and anterior to the angle of the mandible [3] [8] [9]. However some cases may have atypical imaging features or unusual location of this bone defect, makes it necessary to perform computed tomography or magnetic resonance imaging for the correct diagnosis. Magnetic resonance imaging is considered by many authors to be the most efficient method of diagnosis, compared with computed tomography, surgical exploration, panoramic radiography and sialography, as it provides a better differentiation of soft tissues, allowing a more conclusive result, avoiding an unnecessary biopsy [4] [7].

The presumptive and the benignity diagnosis of this lesion is made and suggested by radiological methods such as radiography, computed tomography and magnetic resonance when as characteristics of image demonstrate behavior of low aggressiveness. In our case and corroborating the reports of other cases, after visualization of the lesion by computed tomography and magnetic resonance, we demonstrated that the lesion presents peculiar characteristics such a rounded defect or a well-defined focal depression of mandibular lingual cortical bone with preservation of vestibular cortical bone (Figures 1-3) but in an atypical location of this bone defect (Figure 4). We also demonstrated that the content within lesion is probably composed of vascular and soft tissues, denoting a behavior and a benign composition without signs of malignancy (Figure 2). The patient was followed for one year after the initial diagnosis and the hypothesis of a bone defect or Stafne's cyst was confirmed in an atypical location in the mandible.

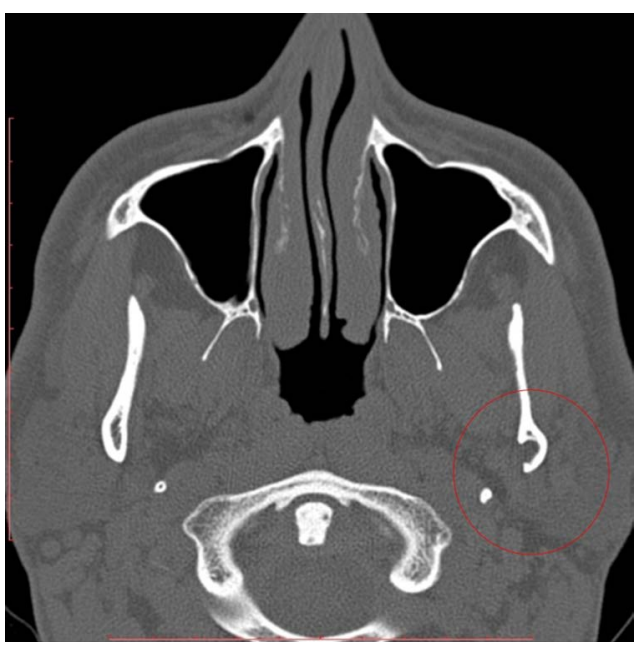

Figure 1. Axial computed tomography (bony window) showing a bone defect in the left mandible ramus (red circle), with adjacent fatty and soft tissue herniated to the inside. 


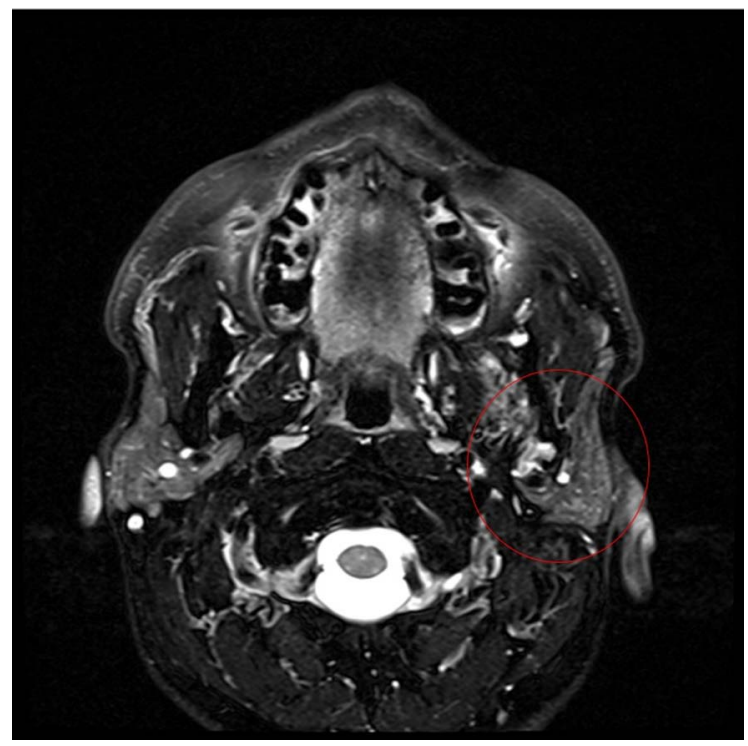

Figure 2. Magnetic resonance with T2 FATSAT sequence demonstrating the bone defect in the left mandible ramus (red circle), with hypersignal areas inside, by probable vascular and soft tissue.

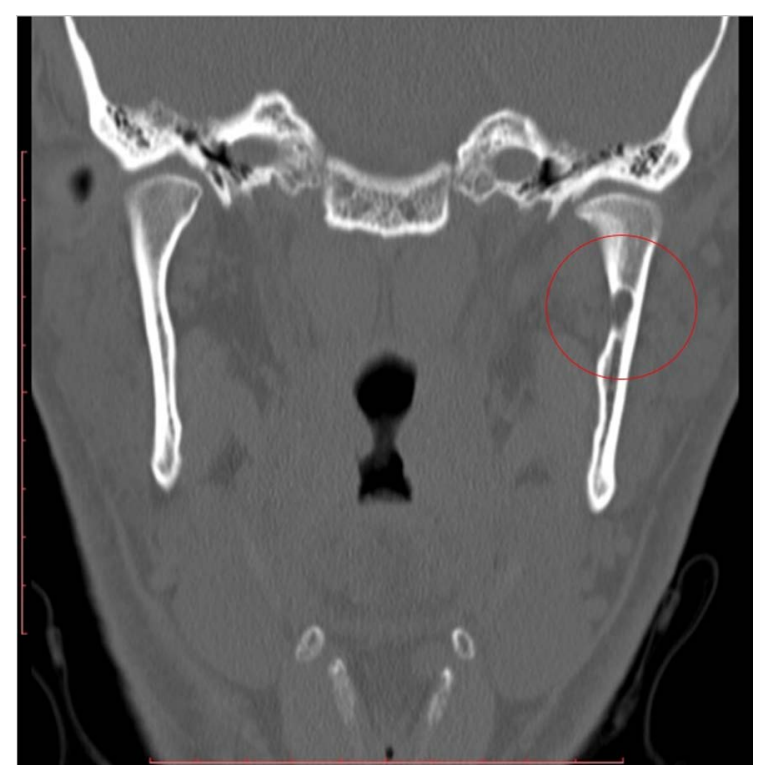

Figure 3. Coronal computed tomography (bone window) demonstrating a circumscribed bone defect at the transition of the subcondylar region and neck of the left mandible ramus (red circle), near the margin of the deep portion of the adjacent parotid.

Differential diagnoses of Stafne's bone defect include benign and malignant lesions such as odontogenic cystic lesions, fibrous dysplasia, vascular lesions, brown tumor of hyperparathyroidism, basal cell nevus syndrome, osteoclastoma, metastasis, aneurysmal and traumatic bone cyst, ameloblastoma and odontogenic keratocystic tumor [9]. 


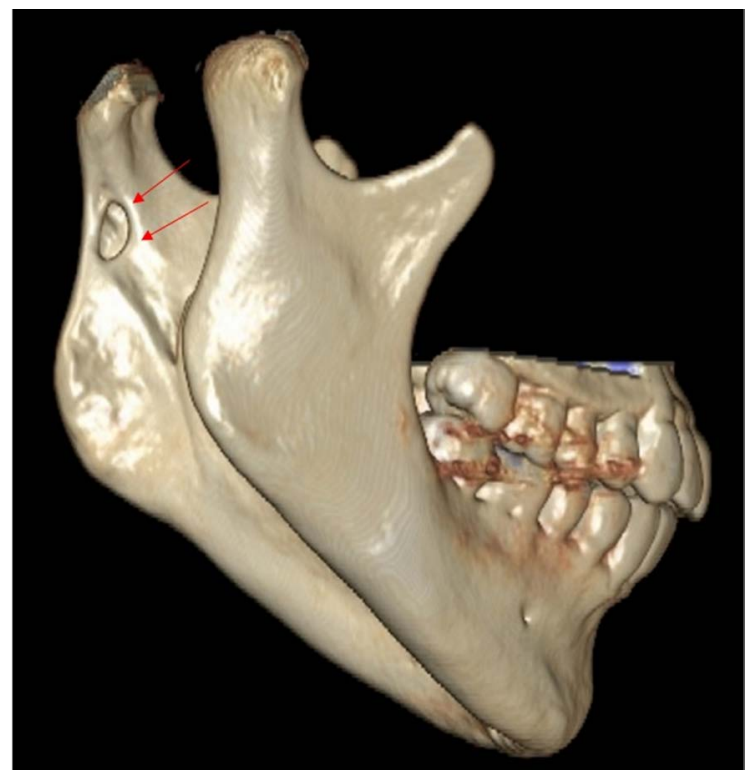

Figure 4. Reconstruction of 3D computed tomography of the mandible region bilaterally, demonstrating a circumscribed bone defect in the transition of the subcondylar region and neck of the left mandible ramus (red arrows).

\section{Conclusion}

We conclude that the report of this case is important for radiologists, dentists and physicians in general, since the knowledge of atypical locations of such benign mandibular bone defects can avoid misdiagnosis or erroneous interpretation and prevent unnecessary surgical or invasive procedures.

\section{Funding}

No funding was used in this work.

\section{Conflict of Interest}

There is no conflict of interest of the authors in this work/document.

\section{References}

[1] Schaerlaken, D.A., Dom, M., Hintjens, J., et al. (2015) Stafne Bone Cavity. Journal of the Belgian Society of Radiology, 98, 137-138. https://doi.org/10.5334/jbr-btr.802

[2] Mourão, C.F.A.B., Mianda, A.M.M.A., Santos, E.J.C., et al. (2013) Lingual Cortical Mandibular Bone Depression: Frequency and Clinical-Radiological Features in a Brazilian Population. Brazilian Dental Journal, 24, 157-162.

https://doi.org/10.1590/0103-6440201302091

[3] Stafne, E.C. (1942) Bone Cavities Situated near the Angle of the Mandible. The Journal of the American Dental Association, 29, 1969-1972.

https://doi.org/10.14219/jada.archive.1942.0315

[4] Branstetter, B.F., Weissman, J.L. and Sheldon, B.K. (1999) Imaging of a Stafne Bone Cavity: What MR Adds and Why a New Name Is Needed. American Journal of 
Neuroradiology, 20, 587-589.

[5] Philipsen, H., Takata, T., Reichart, P., Sato, S., et al. (2002) Lingual and Buccal Mandibular Bone Depressiones: A Review Based on 583 Cases from a World-Wide Literature Survey, including 69 New Cases from Japan. Dentomaxillofacial Radiology, 31, 281-290. https://doi.org/10.1038/sj.dmfr.4600718

[6] Apruzzese, D. and Longoni, S. (1999) Stafne Cyst in an Anterior Location. Journal of Oral and Maxillofacial Surgery, 57, 333-338. https://doi.org/10.1016/S0278-2391(99)90684-5

[7] Grellner, T., Frost, D. and Brannon, R. (1990) Lingual Mandibular Bone Defect: Report of Three Cases. Journal of Oral and Maxillofacial Surgery, 48, 288-296. https://doi.org/10.1016/0278-2391(90)90396-J

[8] Anbiaee, N., Ebrahimi, S., Ebrahimnejad, H., et al. (2016) Stafne Bone Defect in the Ramus of the Mandible: A Case Report. Journal of Dentomaxillofacial Radiology, Pathology and Surgery, 5, 37-41. https://doi.org/10.18869/acadpub.3dj.5.1.37

[9] Turkoglu, K. and Orhan, K. (2010) Stafne Bone Cavity in the Anterior Mandible. Journal Craniofacial Surgery, 21, 1769-1775.

https://doi.org/10.1097/SCS.0b013e3181f40347

\section{Submit or recommend next manuscript to SCIRP and we will provide best service for you:}

Accepting pre-submission inquiries through Email, Facebook, LinkedIn, Twitter, etc. A wide selection of journals (inclusive of 9 subjects, more than 200 journals) Providing 24-hour high-quality service

User-friendly online submission system

Fair and swift peer-review system

Efficient typesetting and proofreading procedure

Display of the result of downloads and visits, as well as the number of cited articles

Maximum dissemination of your research work

Submit your manuscript at: http://papersubmission.scirp.org/

Or contact ojmi@scirp.org 